\title{
Life, death and the power of the Real
}

\section{Ron Mueck}

National Gallery of Canada

Mar. 2-May 6, 2007

$\mathrm{T}$ he exhibition of 16 remarkably realistic figurative sculptures by artist Ron Mueck at the National Gallery of Canada is both stunning and contemplative. Often described as super-real, hyper-real or even ultra-realistic, Mueck's sculptures of the human figure contain such lifelike details that both art critics and the public define his work as extraordinary. Indeed, the wrinkles, moles, body hair, even rashes and stretch marks on his fibreglass and silicone figures have been crafted to such perfection that viewers often claim they instinctively expect his figures to begin breathing.

The interest in understanding his working process and how he achieves these lifelike effects technically (for example, the sculpting, moulding, casting and fabrication processes as well as the efforts involved in punching hundreds of tiny individual pores for individual whiskers and eyebrows) lingers in the minds of most viewers. Moreover, these realistic re-creations of the human figure provoke strong emotional responses in the viewer, who can easily transform these figures into fantastical facsimiles of him or herself.

Mueck's interest in figurative modeling techniques began in Australia where he worked as a puppet maker, both making and animating marionettes for children's television. After supervising special effects for films in the late ig8os and working with renowned puppeteer Jim Henson, Mueck set up his own business in London, England, creating models for $\therefore$ the European advertising industry. After seeing one of Mueck's hyper-realistic sculptures of Pinocchio at the Hayward Gallery in London in 1996, contemporary art collector Charles Saatchi commissioned Mueck to make a group of work for his collec-

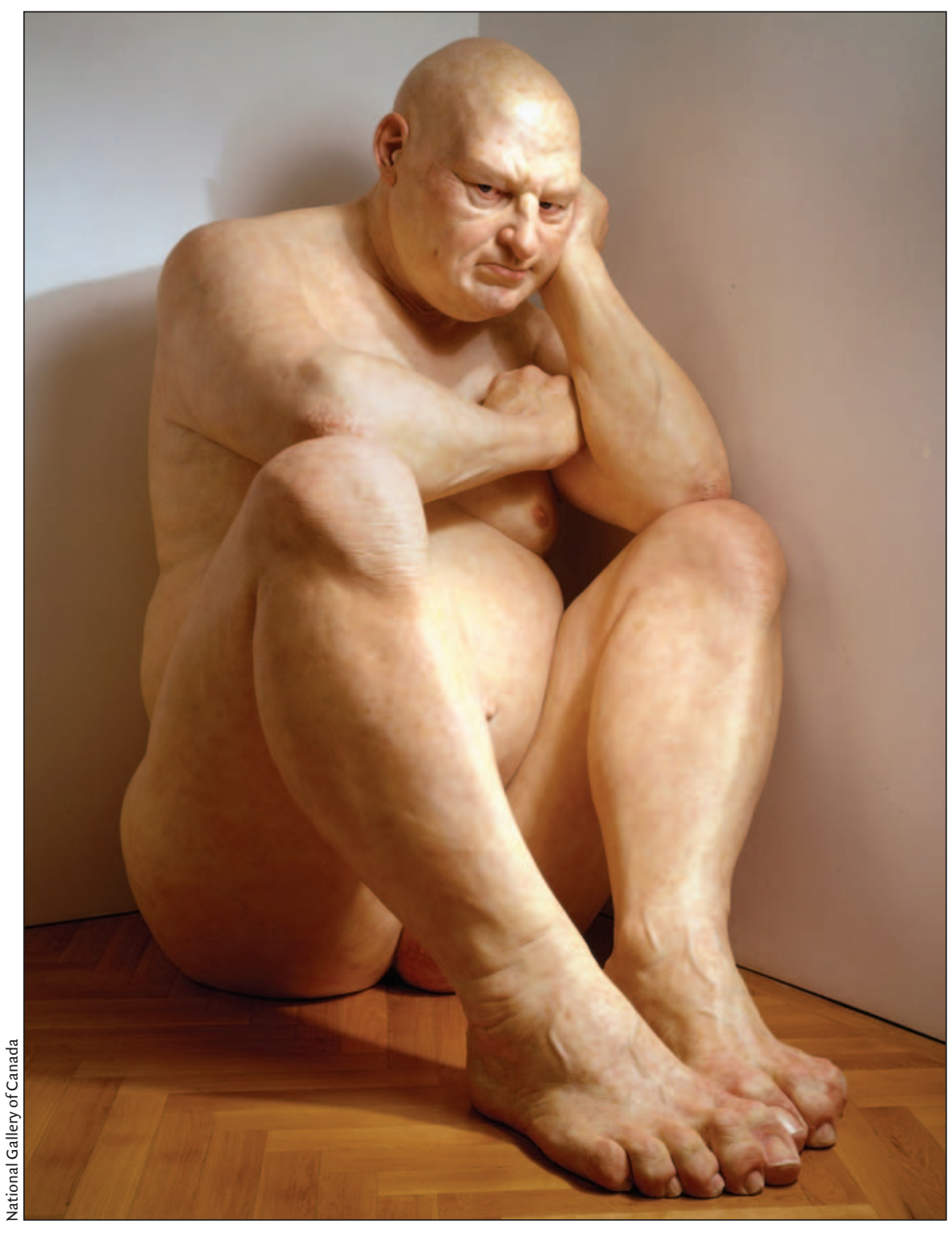

Ron Mueck, Untitled (Big Man) (2000). Courtesy of Hirshhorn Museum and Sculpture Garden, Smithsonian Institution, Washington (DC). Museum purchase with funds provided by the Joseph $\mathrm{H}$. Hirshhorn Bequest and in honor of Robert Lehrman.

tion. A year later, Mueck was included in the celebrated exhibition Sensation: Young British Artists from the Saatchi Collection at the Royal Academy of Arts in London.

Mueck's iconic work from the Sensation exhibition, Dead Dad, is on view in this exhibit at the National Gallery of Canada. Unlike the other sculptures, which Mueck claims were inspired by imagery from art history or magazine photographs, Dead Dad commemorates the moment when the artist heard the news that his father had died. Appearing smaller than lifesized, naked, drained of blood and laid-out on a stark museum platform with the palms of his hands facing upwards, Mueck's rendition of his father's corpse certainly elicits an emotional response. Indeed, many of his works create such a riveting sense of 
realism that they leave an indelible imprint on the viewer, by eliciting memories of one's own experiences. His work creates an imaginative opportunity to reflect upon the themes and cycles of life, death, suffering, longing, loneliness and desire.

This emotional impact related to viewing Mueck's sculptures is heightened by the fact that the artist never chooses to render his figures life-sized. The effect of this altered scale is profound; it changes how we relate to these figures physically and psychologically. In Spooning Couple, a half-lifesize man and woman (I4 $\mathrm{cm}$ by $65 \mathrm{~cm}$ long, $35 \mathrm{~cm}$ wide) lie intimately together semi-nude as if on a bed. Due to their placement on a low pedestal, the viewer is invited to look down on this secluded couple from above and peer ever so closely at their facial expressions and imagine what kind of lives they are living. From this bird's eye view the shrunken sculpture represents a deeply touching depiction of loneliness within intimacy. Each individual is tower above us. Cases in point are the pouting hulk, Big Man, and the 16 foot-long newborn baby, which still has its umbilical cord attached. In these oversized works a certain ambiguity once again comes into play as the figure's vulnerability is intertwined and seemingly reinforced by our own apprehension and empathetic involvement. In this regard, Mueck's "lifelike" sculptures embody, in one way or another, the colossal challenges and manifold perils of the human condition.

The 16 distinctive sculptures, created between 1996 and 2006, are part of an internationally touring exhibit organized by the Fondation Cartier pour l'art contemporain (Paris) in collaboration with the National Gallery of Canada, the Brooklyn Museum and the Scottish National Gallery of Modern Art. This exhibition marks a mid-career retrospective for the artist and is the largest collection of Mueck's works ever assembled in one place. As a relative newcomer who has already attained international ac-

\section{The shrunken sculpture, Spooning Couple, is a deeply touching depic- tion of loneliness within intimacy.}

subtlety and delicately wrapped in their ownself, arms cradling their own body rather than the other's.

Other more imposing figures in the exhibition are enormous (twice, 3 times, even ro times life-size) and claim after only a few years of exhibiting, Mueck has obviously been embraced by an awe-struck public as well as by an enthusiastic group of collectors and institutions.

Though Mueck is not the first artist

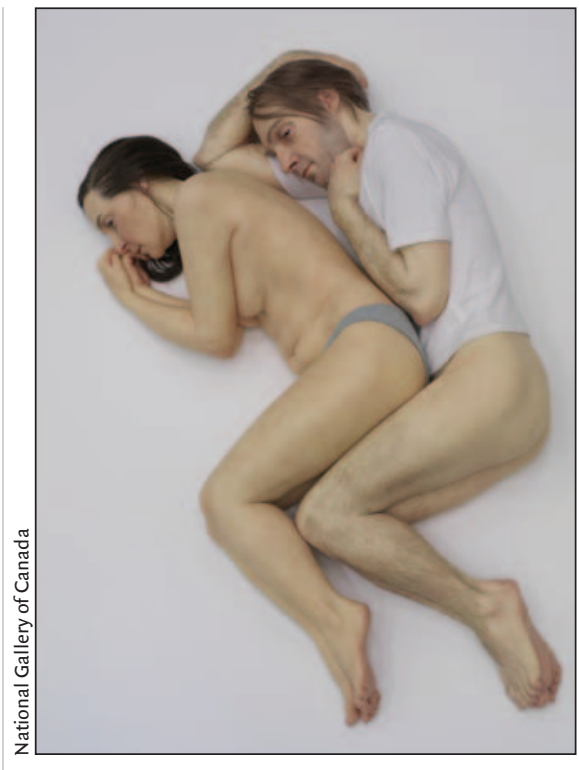

Ron Mueck, Spooning Couple (2005). Mixed media. $14 \times 6_{5} \times 35 \mathrm{~cm}$. Private collection.

to work with realist sculptural techniques in order to focus on humanistic themes, his theatrical works strike me as perhaps fitting within the long and rich artistic tradition of memento mori: artistic creations that remind people of their own mortality. In this regard, Mueck's expressive lifelike figures become allegorical and contemplative contemporary vanitas, modern symbols that both embody and evoke the illusory perfection of reality while simultaneously revealing the painful anxieties about death and the passage of time.

\section{Cindy Stelmackowich}

Art historian

Ottawa, Ont. 